\title{
Would Mothers Relax Their Degree of Selectivity for Supports Suitable for Egg-Laying When the Local Density of Conspecific Females Increases? A Case Study with Three Common Lepidopteran Leaf Miners
}

\author{
Jean Béguinot \\ Entomological Group, Société d'Histoire Naturelle du Creusot, 12 Rue des Pyrénées, 71200 Le Creusot, France \\ Correspondence should be addressed to Jean Béguinot, jean-beguinot@orange.fr
}

Received 23 September 2012; Accepted 15 October 2012

Academic Editors: D. Park and D. J. White

Copyright () 2012 Jean Béguinot. This is an open access article distributed under the Creative Commons Attribution License, which permits unrestricted use, distribution, and reproduction in any medium, provided the original work is properly cited.

\begin{abstract}
Selecting suitable supports for egg-laying, among host species and host individuals, as well as between leaves of various qualities within a preferred host, is a major component of prehatching maternal care in herbivore insects. This feature is especially important for those species having a tightly concealed larval stage, such as leaf miners. Yet, increasing density of neighbouring conspecific females may possibly induce ovipositing mothers to relax their degree of selectivity, so as to distribute their eggs more evenly among host leaves and reduce the risk of future scramble competition between larvae within a same leaf. We test this hypothetical prediction for three common leaf-mining moths: Phyllonorycter maestingella, Phyllonorycter esperella, and Tischeria ekebladella. The prediction was supported by none of the three tested species. This suggests that, in these tiny insect species, mothers are either unable to account for the local density of neighbouring conspecific females and/or they have no effective motivation to react accordingly. In addition, this also suggests that host individuals differing by the average quality of their leaves yet exert no differentiated attractivity towards mothers at a distance. In turn, this emphasizes the role of contingent factors in the patterns of spatial distribution of insects' densities.
\end{abstract}

\section{Introduction}

Prehatching maternal care is common place among herbivore insects since, usually, the larval stage is hardly mobile and the diet of larvae is often limited to a rather narrow range of host plants $[1,2]$. Accordingly, ovipositing mothers ordinarily share the entire and double responsibility of (i) making available the best resource for offspring by selecting appropriately the supports to be egg-laid and (ii) preventing the risk of scramble competition within the brood by limiting the size of egg clutch. This stands all the more strictly for those insects with larval stage tightly concealed within a narrow part of the host plant, such as mine-forming insects [3].

For mothers, in leaf-mining species, the selection of supports to be egg-laid consists not only in reaching the proper host species but, further on, by selecting the most appropriate host individuals and, eventually, the more promising subsets of host leaves that will thus satisfy at best the minimum requirements of mothers after careful probing. The later selective choice is often decisive since leaf quality may vary at least as much within individual hosts than between them [4-9].

In quantitative term, let " $\alpha$ " be the proportion of host leaves that, being probed, would positively answer the level of quality required by egg-laying mothers, that is, the "leaf-acceptance ratio." Then, whether being accepted, the positively probed leaf is egg-laid. Let " $n_{c}$ " be the size of the deposited egg clutch (or, hereafter, the number of monooccupied mines resulting from the hatching of a clutch of eggs: the "mines-clutch size").

Such a "prehatching maternal care", involving constraining limitations upon both the leaf-acceptance ratio " $\alpha$ " and the clutch-size " $n_{c}$ ", is real mother investment since both limitations contribute to slow down the progress of 
oviposition, which, in turn, may become a serious constraint upon mothers, in a context of limited time expenditure [10].

Moreover, the cooccurrence of conspecific ovipositing females in the immediate vicinity may likely exerts a supplementary constraint on mothers, as far as this cooccurrence is acknowledged by them $[11,12]$. In order to prevent the increased risk of future scramble competition between larvae, mothers may then be induced to decrease further (if possible) the clutch-size " $n_{c}$ " and also somewhat relax the severity of leaf-selection (increasing the leaf-acceptance " $\alpha$ ").

Such supplementary tuning of mothers' behaviour, as an answer to the hypothetical perception of the concurrence from conspecific females, may have obvious implications in terms of density-dependent source of regulation of insects' populations.

At first, it should be noticed that, most often, the densities of leaf miners, in field conditions, are low enough for the risk of scramble competition being quite limited [13-15]. However, in yet nonexceptional circumstances, the proportion of host leaves supporting more than one mine may become significant and the resulting cooccurrence has been reported detrimental for the development and survival of progeny $[14,16]$.

Now, the cooccurrence of conspecifics can be mediated several ways, in particular via the frequencies of mother's encounters with either previously deposited eggs or with other conspecific mothers also present within the host canopy (without prejudice, in addition, of possible indirect mediations by the host plant or by shared natural enemies: [17]).

In tiny insects such as leaf miners, it is commonly considered that mother would generally not recognise previous egg deposits $[9,13-15,18-25]$. Yet, this point, that is, the insensitivity of mothers to conspecifics' eggs density, was positively rechecked for each sample considered in this study, by controlling the variance to the mean ratio to be always $>1$.

This, however, does not rule out the second alternative, that is, mothers' sensitivity to the local density of conspecifics. Although being unable to recognise the presence of minute eggs deposits on leaves, mothers might, yet, be able to more easily recognise the presence of conspecific females in their neighbourhood and might be sensitive to their relative density in the patch of host leaves. Thus, when mothers' densities are not too low, the perception of conspecifics seems not unlikely a priori and the possible resulting reaction of mothers, in terms of reducing either their degree of selectivity among host leaves or their clutch size (or both) ought to be considered and tested.

We address this issue, considering three moth species (Phyllonorycter maestingella, Phyllonorycter esperella, and Tischeria ekebladella) mining, respectively, three major European host-tree species (beech, hornbeam, and oak, resp.). For each moth species, several sites (from 6 to 22) were selected in consideration of their relatively high (while noneruptive) average numbers of mines per leaf, the latter varying in a range sufficiently large to test efficiently for the possible influence of the density of neighbouring conspecific females. As the average value of clutch size in leaf-mining insects is ordinarily close to unity; this parameter offers only a tenuous opportunity for further reduction under the hypothetic influence of neighbouring conspecifics. Therefore, we focus specifically upon the possible positive answer of the leafacceptance ratio " $\alpha$ " to the local density of conspecific females. The rationale behind such an answer is that increasing the leaf-acceptance ratio would proportionally reduce the average eggs' density per leaf, so that mothers may be induced to relax the severity of leaf selection prior to egg laying as a response to increasing density of conspecific females around. In the same perspective, we test whether local density of mothers correlate, with average habitat quality or not.

\section{Methods}

2.1. Estimation of the Quantitative Traits of Egg-Laying Behaviour: $\alpha, n_{c}$, and $\mu$. The proportion of host leaves actually accepted by mothers and then egg-laid is rather easily checked in the field. Yet, this ratio has evidently no univocal significance in terms of mothers' behaviour since it depends not only upon the degree of selectivity of mothers but also upon their unknown local density and, accordingly, may not at all serve as a surrogate for estimating the behaviourally relevant ratio of leaf-acceptance " $\alpha$." While " $\alpha$ " is virtually impossible to record, at least under field conditions, it may be estimated indirectly, using an appropriate inferential method, the "Melba" procedure.

In short (see [26, 27] Béguinot 2011, 2012 for details), this procedure relates the hard-to-observe parameters $\alpha$ and $n_{c}$ to the easily field-recorded distribution $\Pi(\eta)$ of the numbers of leaves according to the number $y$ of either eggs or mines they support. Briefly, the procedure is based on the fact that, thanks to acceptable simplifying assumptions (see appendices), the distribution $\Pi(\eta)$ should theoretically answer a specific equation with $\alpha$ and $n_{c}$ as the adaptable parameters. Conversely, the inferred values for $\alpha$ and $n_{c}$ are those that yield the best fit between the recorded distribution $\Pi(\eta)$ and the corresponding theoretical distributions $\Pi(\eta)$, parameterised in terms of $\alpha$ and $n_{c}$. In turn, the estimated average number $\mu$ of mothers' probing visits per leaf is derived, dividing the recorded average number of mines per leaf by $\left(\alpha \cdot n_{c}\right)$.

The "Melba" procedure is rapid and easy to run and, therefore, reveals particularly appropriate when a large series of samples are to be analysed, as is the case here.

Now, the average local density of mothers within the sampled portion of the host canopy is also a factor very difficult to monitor in the field. Yet, it is likely that increasing (resp., decreasing) the local density of egg-laying mothers would directly result in an increase (resp., decrease) of the average number $\mu$ of mothers' probing visits received per host leaf. The hypothetical dependence of the leaf-acceptance $\alpha$ upon the local density of mothers may thus be tested by considering the hypothetical dependence of $\alpha$ upon $\mu$.

2.2. Field Data. At first, it should be noticed that the notion of mothers relaxing their degree of selectivity as an answer to an increase of their local density makes all the more sense that this local density of females-and the resulting value 
of $\mu$-are high. Accordingly, relatively high levels of mining impact were selected for this study (from 0.10 to 0.88 mine per leaf), so that the average number $\mu$ of mothers' probing visits to host leaves is also high, comprised between 0.1 and 1.5 visits per leaf. This is just below the threshold level for the occurrence of nascent eruptive outbreaks, (i.e., impacts $>1$ mine/leaf: see [16]). Note that such outbreaks are quite infrequent in the three species considered here and even slightly lower ranges of impacts, say between 1.0 and 0.1 mine per leaf, as is the case here, are not met so commonly. This, indeed, makes the practical difficulty to gather appropriate samples as numerous as desired and to cover a larger range of leaf-mining species, including less common taxa.

Host-trees canopies were sampled in the centre of France, mainly, south Burgundy, from August to November; a total of 34 different stands were sampled, and 14118 leaves were examined, supporting a total of 4502 mines. The repartition of samplings and observations according to leafmining species is as follows: Phyllonorycter maestingella (Müller, 1764) on Fagus sylvatica L.—22 stands, 10146 leaves with 2726 mines; Phyllonorycter esperella (Goeze, 1783) on Carpinus betulus L.—6 stands, 2473 leaves with 1355 mines; Tischeria ekebladella (Bjerkander, 1795) on Quercus sessiliflora (Sm.)—6 stands, 1499 leaves with 421 mines.

\section{Results}

The leaf-acceptance ratio $\alpha$ is plotted, Figure 1, against the average number $\mu$ of mothers' probing visits per leaf for each of the three studied leaf-mining moths, Phyllonorycter esperella, Phyllonorycter maestingella, and Tischeria ekebladella. At any given level of females' local density, that is, at any corresponding value $\mu$, the leaf-acceptance ratio $\alpha$ shows a relatively large scatter. Yet, aside this dependence of $\alpha$ upon the average level of foliar quality of each particular host-individual (and may be also aside some intraspecific variability in mothers' requirements $[28,29]$, the leafacceptance ratio shows no more than a weak dependence (if any) upon the density $\mu$ of mothers' probing visits, and, thus, upon the local density of conspecific egg-laying females in the sampled portion of canopy. For all three species under study, $r^{2}$ is near zero: Phyllonorycter maestingella: $r^{2}=0.07$, $n=22$; Phyllonorycter esperella: $r^{2}=0.02, n=6$; Tischeria ekebladella: $r^{2}=0.02, n=6$.

\section{Discussion}

The oviposition pressure, resulting from the local density of conspecific females, may possibly influence the behaviour of egg-laying mothers through (i) the ability of mothers to detect directly the occurrence of previously deposited conspecific eggs or (ii) their capacity to account for the density of neighbouring conspecific females themselves.

The first alternative is generally considered unlikely within most tiny leaf-mining species with very minute eggs, as mentioned above, and this was actually verified in each case in the present study. The second, independent alternative, on the contrary, had to be considered and was tested accordingly (using the average density $\mu$ of mothers' probing

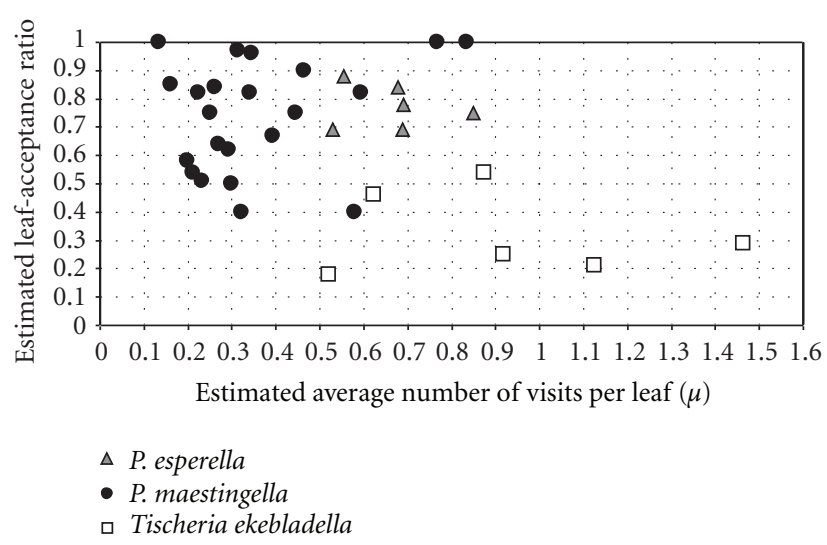

Figure 1: The leaf-acceptance ratio $\alpha$ plotted against the average number of mothers visits per leaf $\mu$ for three species of leaf-mining moths on woody dicots: Phyllonorycter esperella, Phyllonorycter maestingella, and Tischeria ekebladella.

visits to leaves as a proportional proxy for the local density of conspecific females).

As mentioned above, the leaf acceptance ratio $\alpha$ answers two causal components, as it depends upon both (i) the insect own degree of selectivity, that is, the threshold level of mothers' requirement regarding the host leaves properties making them acceptable for subsequent egg-laying and (ii) the average quality of displayed host leaves (as viewed "in the eyes of mothers" [30]), that is, the proportion of those host leaves which met the threshold level of mothers' requirement.

The rationale behind a hypothetic relationship between $\alpha$ and $\mu$ is thus twofold:

(i) as already underlined, mothers may increase the proportion $\alpha$ of acceptable leaves by relaxing their minimum requirement level for host leaf quality. A larger proportion of acceptable leaves would counteract the growing oviposition pressure $\mu$ due to an increased local density of conspecific females and the related risk of stronger future scramble competition between larvae;

(ii) reciprocally, one can imagine that a given host individual with a higher average quality of leaves, resulting in a higher ratio of leaf acceptability $\alpha$, may hypothetically "attract" more females from a distance and then contribute to increase their local density and the resulting oviposition pressure $\mu$.

Now, according to the results of the regression of the leaf-acceptance $\alpha$ against the density $\mu$ of mothers' probing visits, taken as a proxy for the related density of neighbouring females (Figure 1), the latter factor $\mu$ explains only less than $10 \%$ of the variance of the leaf-acceptance ratio, respectively, 7\%, 2\%, and 2\% for Phyllonorycter maestingella, Phyllonorycter esperella, and Tischeria ekebladella. As might be expected, the major, remaining part of the variance of the leaf acceptability $\alpha$, at given $\mu$, is likely resulting from variations of the average quality of leaves between the different sampled host individuals of the same species 
$[2,12,15,31-35]$. In addition, the degree of mothers' requirement for leaf acceptability may also somewhat vary among sampled sites. Yet, this second contribution to the variance of $\alpha$ is thought to be quite less than that liable to hosts' variability.

Note also that the quasi-independence of the leafacceptance $\alpha$ upon the local density of mothers cannot result from a mutual cancel of the two influences hypothesised above ((i) and (ii)) since both influences would lead to a dependence of $\alpha$ upon $\mu$ with the same (positive) sign. Accordingly, both hypotheses above reveal inconsistent. This suggests, at least for the three species under study,

(i) that in such tiny insects, mothers are either unable to account for the local density of their neighbouring conspecifics, or they have no substantial motivation to react accordingly;

(ii) that if mothers are able to detect their preferred hostplant species at some distance, they yet seem unable to evaluate at a distance the average level of the quality of the foliage, or they show no motivation to take advantage of that. Thus, the hypothesis of a differentiated attractivity on mothers of host individuals according to their average leaf quality is not supported. This, in turn, puts supplementary emphasis upon the arguably predominant role of contingent factors in the often strongly uneven patterns of spatial distribution of insects densities (Tack, personal communication).

Enlarging the range of studied species in these respects would remain desirable since a direct sensitivity and answer of egg-laying mothers to the local density of their conspecifics may not be excluded for some other species, even perhaps for some species among tiny microlepidopterans.

\section{Appendices}

\section{A. The Three Basic Assumptions Rooting the "Melba" Procedure}

The following points are assumed (and, yet, systematically checked for the third point):

(i) random distribution of mothers' probing visits among host modules (here host leaves). Of course, this is no longer the case for efficient visits, that is, concluded by ovipositions, as soon as not all modules are acceptable, that is, $\alpha<1$. This first assumption is commonly referred to for these kinds of herbivore insects $[18,23,36-40]$;

(ii) equiprobability of mothers' probing visits among modules; the differences which may actually exist between the probabilities of visits, for example, in relation to variations of the individual size of modules, are neglected as a first approximation, as far as all these modules belong to the same type and represent the same "space module" for the insect, according to the observations of Digweed [24], the argumentation of Kuczyński and Skoracka [41] and Gripenberg and Roslin [25]. Indeed, such simplifications are commonly used in models, see for example, Kagata and Ohgushi [42] for leaf miners or Kuczyński and Skoracka [41] for leaf gallers;

(iii) those insect species only are considered, for which mothers do not decidedly avoid nor restrict oviposition upon modules already visited and egg-laid previously by themselves or conspecifics [13-15, 18$20,22-25,43,44]$. As this third assumption may not always be verified; however, implementing the "Melba" procedure should be discarded when the distribution of the numbers of eggs per acceptable unit has a variance significantly lower than the mean, thus suggesting a trend for some avoidance of cumulative egg deposits on a same module.

\section{B. Brief Summary of the Rationale of Melba Procedure}

According to the two first assumptions above (i.e., random distribution and equiprobability of probing visits among leaves), the distribution of the number of probing visits received per host leaf would ideally conforms to a Poisson law. Now, among all these probing visits, only those received by potentially acceptable leaves, according to mothers' requirements, are concluded by an egg clutch deposit: the reason why, at the difference of the distribution of visits, the distribution of eggs deposits (and associated offspring) within the whole set of sampled leaves is not conformed to, and more aggregated than, Poisson.

Conformity to Poisson law of the distribution of eggdeposits is expected only within the set of potentially acceptable leaves (on proviso of the third assumption above being satisfied, since then, mothers do not avoid ovipositing upon leaves already previously egg-laid.

Then, let $\Pi(v)$ be the proportion of leaves that received $v$ "efficient" visits (each one concluded by an egg clutch deposit), among the whole set of $n_{u}$ sampled leaves.

For $v \neq 0$, that is, leaves having received at least one "efficient" visits, only the acceptable ones are concerned, by definition. Then, $\Pi(v)$ is given by applying the Poisson law to the set of potentially acceptable host leaves only, which represent a proportion $\alpha$ of the whole set of displayed leaves. Accordingly, for $v \neq 0$ :

$$
\Pi(v)=\frac{\alpha \cdot \exp (-\mu) \cdot \mu^{v}}{v !} \quad(v \neq 0) .
$$

For $v=0$, that is, leaves having received no efficient visit, two contributions are to be considered: all the nonacceptable leaves (proportion $(1-\alpha)$ ) and also those acceptable leaves that, by chance, have received no visits:

$$
\Pi(v)=1-\alpha+\alpha \cdot \exp (-\mu) \quad(\text { for } v=0),
$$

with $\mu$ as the average number of probing visits received per host leaf ( $\mu$ is, as well, the average number of "efficient" visits received per potentially acceptable leaf). 
Now, what may be observed and quoted a posteriori in the field is not the number of efficient visits per leaf but their direct material consequences (the "recorded objects") in terms of the number $\mathrm{y}$ per host leaf of either deposited eggs or resulting larvae (or alternatively the number of associated "artefacts" such as mines or galls). Accordingly, the clutchsize $n_{c}$ may either apply to deposited eggs or the resulting artefacts.

If deposited eggs are the objects directly recorded in the field, then $n_{c}$ corresponds to the usual definition of clutch size: the number of eggs deposited in a single bout.

If resulting artefacts (mines, galls, etc.) are now the more easily recorded objects, then $n_{c}$ is the average number of these "residual" artefacts resulting from one clutch of eggs; in this case $n_{c}$ (the "residual" clutch-size) might be lower than the egg clutch size itself, depending on the ratio of developmental success of eggs.

The number $\mathrm{y}$ of eggs or artefacts per leaf is thus $\eta=v$. $n_{c}$, with $v$ as the number of visits received and $n_{c}$ being either the "eggs" or the "artefacts" clutch size. The proportion $\Pi(\mathrm{y})$ of host leaves supporting $\mathrm{y}$ eggs or artefacts, among the whole sample of $n_{u}$ host leaves, is therefore obtained by substituting $\mathrm{y} / n_{c}$ to $v$, in (B.1) and (B.1)':

(i) for any full positive values of $\left(\mathrm{y} / n_{c}\right)$, that is, for acceptable leaves visited at least once:

$$
\Pi(\mathrm{\eta})=\frac{\alpha \cdot \exp (-\mu) \cdot \mu^{\left(\mathrm{y} / n_{c}\right)}}{\left(\mathrm{y} / n_{c}\right) !},
$$

(ii) and for $\mathrm{y}=0$ :

$$
\Pi(0)=1-\alpha+\alpha \cdot \exp (-\mu) .
$$

The average number $\mu$ of "efficient" visits per acceptable leaf, is given by

$$
\mu=\frac{\left(n_{e} / n_{c}\right)}{\left(\alpha \cdot n_{u}\right)}=\frac{n_{e}}{\left(\alpha \cdot n_{c} \cdot n_{u}\right)},
$$

with $n_{e}$ as the total number of eggs (or total number of resulting artefacts: mines/galls) within the whole studied sample of $n_{u}$ potential host leaves (acceptable or not) (note that considering either eggs or associated artefacts does not modify neither $\left(n_{e} / n_{c}\right)$ nor $\mu$, since, correspondingly, $n_{c}$ is the clutch size applied to either eggs or their resulting artefacts. Therefore, the acceptance ratio $\alpha$ also remains unchanged since $\left.\alpha=\left(n_{e} / n_{c}\right) /\left(\mu \cdot n_{u}\right)\right)$.

The estimation of both $n_{c}$ and $\alpha$ is obtained by comparing the field-recorded distribution $\Pi(\mathrm{y})$ (established for either eggs or their resulting artefacts) to the corresponding computed distribution $\Pi(\eta)$.

In practice, this estimation is obtained iteratively, seeking for the set of values $\left\{n_{c} \& \alpha\right\}$ which leads to the best fit between field-recorded and computed distributions $\Pi(\eta)$. It should remain in mind that, as already mentioned, $n_{c}$ corresponds either to the eggs' or to the mines/galls' clutchsize.
The average number $\mu$ of egg-laying mothers probing visits per host leaf (and as well the average number of clutch deposits per potentially acceptable leaf) is

$$
\mu=\frac{\left(n_{e} / n_{u}\right)}{\left(\alpha \cdot n_{c}\right)},
$$

see (B.3).

\section{Acknowledgment}

The advices of three anonymous reviewers, which substantially improved the paper, are deeply acknowledged.

\section{References}

[1] P. Jolivet, Insectes et Plantes: Evolution Parallèle et Adaptation, Société Linnéenne de Lyon, 1983.

[2] Dajoz, "Quelques aspects des relations plantes-insectes, leur importance dans la dynamique des populations d'insectes phytophages," Cahiers des Naturalistes, vol. 48, pp. 87-103, 1993.

[3] S. H. Faeth, "Novel aspects of host tree resistance to leaf miners," in Forest Insects Guilds: Patterns of Interaction with Host Trees, Y. N. Baranchikov, W. J. Mattson, F. P. Hain, and T. L. Payne, Eds., Tech. Rep, NE-153, pp. 219-239, United States Department of Agriculture. Forest Service, 1991.

[4] J. C. Schultz, P. J. Nothnagle, and I. T. Baldwin, "Seasonal and individual variation in leaf quality of two northern hardwoods tree species," American Journal of Botany, vol. 69, no. 5, pp. 753-759, 1982.

[5] J. C. Schultz, "Habitat selection and foraging tactics of caterpillars in heterogeneous trees," in Variable Plants and Herbivores in Natural and Managed Systems, R. F. Denno and M. S. McClure, Eds., pp. 61-90, Academic Press, New York, NY, USA, 1983.

[6] J. J. Boomsma, H. Timmermans, C. P. M. Corvers, and J. Kabout, "Monophagous leaf-mining larvae of Stigmella (Lepidoptera: Nepticulidae) on birch: patterns and differentiation in exploitation of the host," Holarctic Ecology, vol. 10, no. 3, pp. 206-218, 1987.

[7] M. V. Kozlov and Y. G. Koricheva, "The within-tree distribution of caterpillarmines," in Forest Insects Guilds: Patterns of Interaction with Host Trees, Y. N. Baranchikov, W. J. Mattson, F. P. Hain, and T. L. Payne, Eds., Tech. Rep, NE-153, United States Department of Agriculture. Forest Service, 1991.

[8] T. Roslin, S. Gripenberg, J.-P. Salminen et al., "Seeing the trees for the leaves-oaks as mosaics for a host-specific moth," Oikos, vol. 113, no. 1, pp. 106-120, 2006.

[9] S. Gripenberg, Spatial ecology of a specialist insect herbivorethe leaf-mining moth Tischeria ekebladella on the pedunculate oak Quercus robur [Ph.D. thesis], Helsinki, Finland, 2007.

[10] D. Reavey and K. J. Gaston, "The importance of leaf structure in oviposition by leaf-mining microlepidoptera," Oikos, vol. 61, no. 1, pp. 19-28, 1991.

[11] D. T. Quiring and J. N. McNeil, "Exploitation and interference intraspecific larval competition in the dipteran leaf miner, Agromyza frontella (Rondani)," Canadian Journal of Zoology, vol. 62, no. 3, pp. 421-427, 1984.

[12] T. L. Bultman and S. H. Faeth, "Experimental evidence for intraspecific competition in a lepidopteran leaf miner," Ecology, vol. 67, no. 2, pp. 442-448, 1986. 
[13] T. Cornelissen and P. Stiling, "Clumped distribution of oak leaf miners between and within plants," Basic and Applied Ecology, vol. 9, no. 1, pp. 67-77, 2008.

[14] A. J. M. Tack, O. Ovaskainen, P. J. Harrison, and T. Roslin, "Competition as a structuring force in leaf miner communities," Oikos, vol. 118, no. 6, pp. 809-818, 2009.

[15] A. J. M. Tack, Spatial ecology of an oak-associated herbivore community [Ph.D. thesis], University of Helsinki, Helsinki, Finland, 2010.

[16] M. Auerbach, E. F. Connor, and S. Mopper, "Minor miners and major miners: population dynamics of leaf-mining insects," in Population Dynamics: New Approaches and Synthesis, N. Cappuccino and P. W. Price, Eds., pp. 83-110, Academic Press, New York, NY, USA, 1995.

[17] T. Ohgushi, "Indirect interaction webs: herbivore-induced effects through trait change in plants," Annual Review of Ecology, Evolution, and Systematics, vol. 36, pp. 80-105, 2005.

[18] T. Sugimoto, "Models of the spatial pattern of egg population of Ranunculus leaf mining fly, Phytomyza ranunculi (Diptera: Agromyzidae), in host leaves," Researches on Population Ecology, vol. 22, no. 1, pp. 13-32, 1980.

[19] M. Auerbach and D. Simberloff, "Oviposition site preference and larval mortality in a leaf-mining moth," Ecological Entomology, vol. 14, no. 2, pp. 131-140, 1989.

[20] T. A. Green and R. J. Prokopy, "Oviposition behaviour of the apple blotch leafminer, Phyllonorycter crataegella (Clemens) (Lepidoptera: Gracillariidae)," Journal of the New York Entomological Society, vol. 99, no. 4, pp. 654-663, 1991.

[21] T. P. Craig, J. K. Itami, C. Shantz, W. G. Abrahamson, J. D. Horner, and J. V. Craig, "The influence of host plant variation and intraspecific competition on oviposition preference and offspring performance in the host races of Eurosta solidaginis," Ecological Entomology, vol. 25, no. 1, pp. 7-18, 2000.

[22] J. T. Cronin, W. G. Abrahamson, and T. P. Craig, "Temporal variation in herbivore host-plant preference and performance: constraints on host-plant adaptation," Oikos, vol. 93, no. 2, pp. 312-320, 2001.

[23] H. Kagata and T. Ohgushi, "Effects of multiple oviposition on clutch size in a leaf-mining moth, Paraleucoptera sinuella (Lepidoptera: Lyonetiidae)," Entomological Science, vol. 5, no. 4, pp. 407-410, 2002.

[24] S. C. Digweed, "Oviposition preference and larval performance in the exotic birch-leafmining sawfly Profenusa thomsoni," Entomologia Experimentalis et Applicata, vol. 120, no. 1, pp. 41-49, 2006.

[25] S. Gripenberg and T. Roslin, "Host plants as islands: resource quality and spatial setting as determinants of insect distribution," Annales Zoologici Fennici, vol. 42, no. 4, pp. 335-345, 2005.

[26] J. Béguinot, "Comparison of the severity of selection among beech leaves prior to egg-laying between a leaf-mining and two gall-inducing insects," European Journal of Entomology, vol. 108, no. 1, pp. 71-78, 2011.

[27] J. Béguinot, "Quantifying the gap between the actual incidence of leaf-mining or leaf-galling insects and the proportion of host-leaves potentially acceptable by them," Annales Société Entomologique de France, vol. 48, no. 1-2, pp. 216-224, 2012.

[28] T. Hirota and Y. Kato, "Influence of visual stimuli on host location in the butterfly, eurema hecabe," Entomologia Experimentalis et Applicata, vol. 101, no. 2, pp. 199-206, 2001.

[29] K. Gotthard, N. Margraf, and M. Rahier, "Geographic variation in oviposition choice of a leaf beetle: the relationship between host plant ranking, specificity, and motivation,"
Entomologia Experimentalis et Applicata, vol. 110, no. 3, pp. 217-224, 2004.

[30] S. Gripenberg, J.-P. Salminen, and T. Roslin, "A tree in the eyes of a moth-temporal variation in oak leaf quality and leafminer performance," Oikos, vol. 116, no. 4, pp. 592-600, 2007.

[31] S. Eber, "Bottom-up density regulation in the holly leaf-miner Phytomyza ilicis," Journal of Animal Ecology, vol. 73, no. 5, pp. 948-958, 2004.

[32] K. J. Gaston, D. R. Genney, M. Thurlow, and S. E. Hartley, "The geographical range structure of the holly leaf-miner. IV. Effects of variation in host-plant quality," Journal of Animal Ecology, vol. 73, no. 5, pp. 911-924, 2004.

[33] S. J. Gonçalves-Alvim, R. G. Collevatti, and G. W. Fernandes, "Effects of genetic variability and habitat of Qualea parviflora (Vochysiaceae) on herbivory by free-feeding and gall-forming insects," Annals of Botany, vol. 94, no. 2, pp. 259-268, 2004.

[34] J. A. Santiago Lastra, L. E. García Barrios, J. C. Rojas, and H. Perales Rivera, "Host selection behavior of Leptophobia aripa (Lepidoptera: Pieridae)," Florida Entomologist, vol. 89, no. 2, pp. 127-134, 2006.

[35] S. P. Egan and J. R. Ott, "Host plant quality and local adaptation determine the distribution of a gall-forming herbivore," Ecology, vol. 88, no. 11, pp. 2868-2879, 2007.

[36] E. F. Connor, E. Hosfield, D. A. Meeter, and X. Niu, "Tests for aggregation and size-based sample-unit selection when sample units vary in size," Ecology, vol. 78, no. 4, pp. 12381249, 1997.

[37] U. Kuhlmann, D. Babendreier, T. S. Hoffmeister, and N. J. Mills, "Impact and oviposition behaviour of Ageniaspis fuscicollis (Hymenoptera: Encyrtidae), a polyembryonic parasitoid of the apple ermine moth, Yponomeuta malinellus (Lepidoptera: Yponomeutidae)," Bulletin of Entomological Research, vol. 88, no. 6, pp. 617-625, 1998.

[38] D. Wool and O. Ben-Zvi, "Population ecology and clone dynamics of the galling aphid Geoica wertheimae (Sternorrhyncha: Pemphigidae: Fordinae)," European Journal of Entomology, vol. 95, no. 4, pp. 509-518, 1998.

[39] M. Vos and L. Hemerik, "Linking foraging behavior to lifetime reproductive success for an insect parasitoid: adaptation to host distributions," Behavioral Ecology, vol. 14, no. 2, pp. 236245, 2003.

[40] A. R. Ives and H. C. J. Godfray, "Phylogenetic analysis of trophic associations," The American Naturalist, vol. 168, no. 1, pp. E1-E14, 2006.

[41] L. Kuczyński and A. Skoracka, "Spatial distribution of galls caused by Aculus tetanothrix (Acari: Eriophyoidea) on arctic willows," Experimental and Applied Acarology, vol. 36, no. 4, pp. 277-289, 2005.

[42] H. Kagata and T. Ohgushi, "Conflict between optimal clutch size for mothers and offspring in the leaf miner, Leucoptera sinuella," Ecological Entomology, vol. 29, no. 4, pp. 429-436, 2004.

[43] S. H. Faeth, "Aggregation of a leafminer, Cameraria sp. nov. (Davis): consequences and causes," Journal of Animal Ecology, vol. 59, no. 2, pp. 569-586, 1990.

[44] S. Gripenberg, E. Morriën, A. Cudmore, J. P. Salminen, and T. Roslin, "Resource selection by female moths in a heterogeneous environment: what is a poor girl to do?" Journal of Animal Ecology, vol. 76, no. 5, pp. 854-865, 2007. 

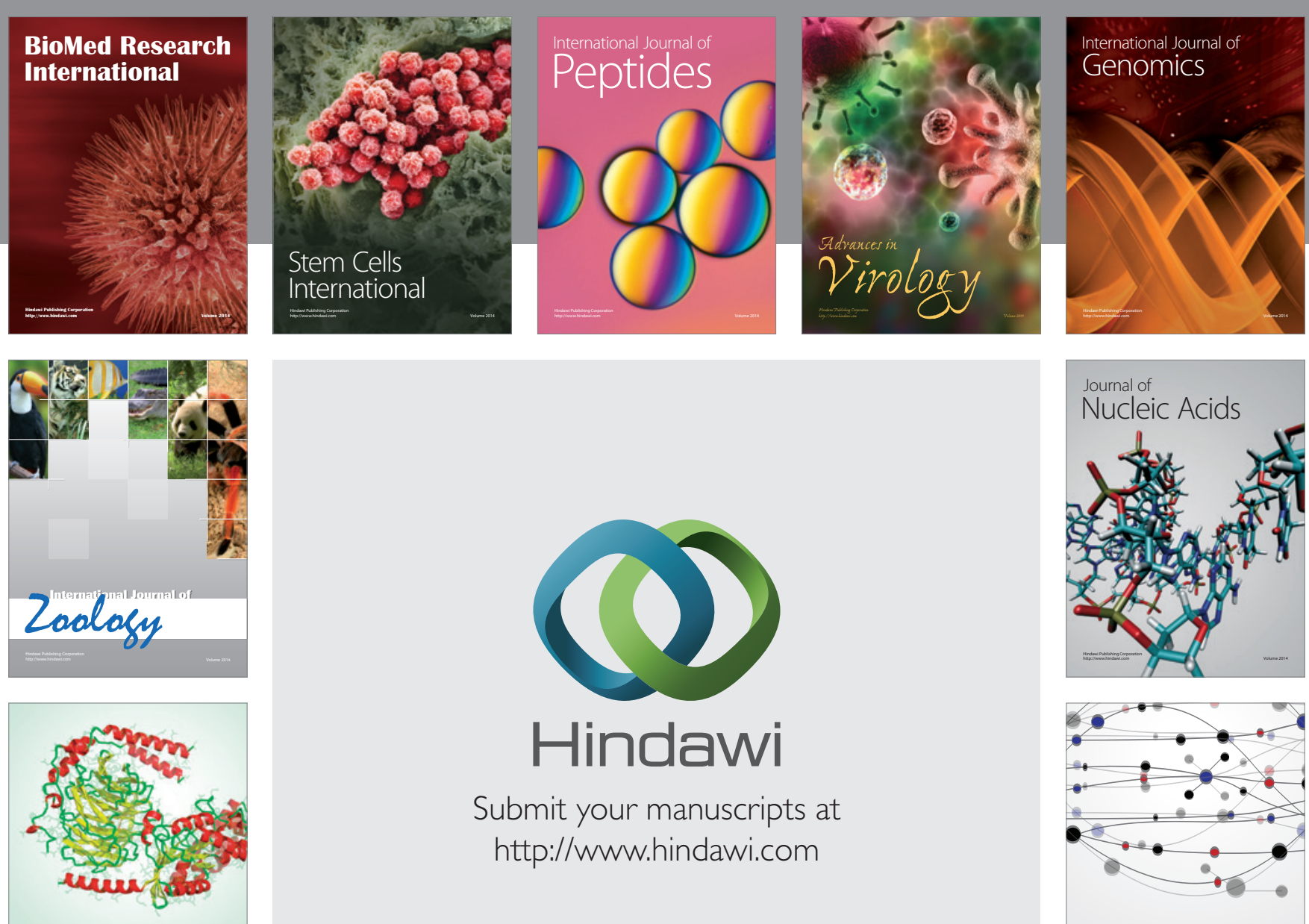

Submit your manuscripts at

http://www.hindawi.com

Signal ${ }^{\text {Jumal }}$ Transduction
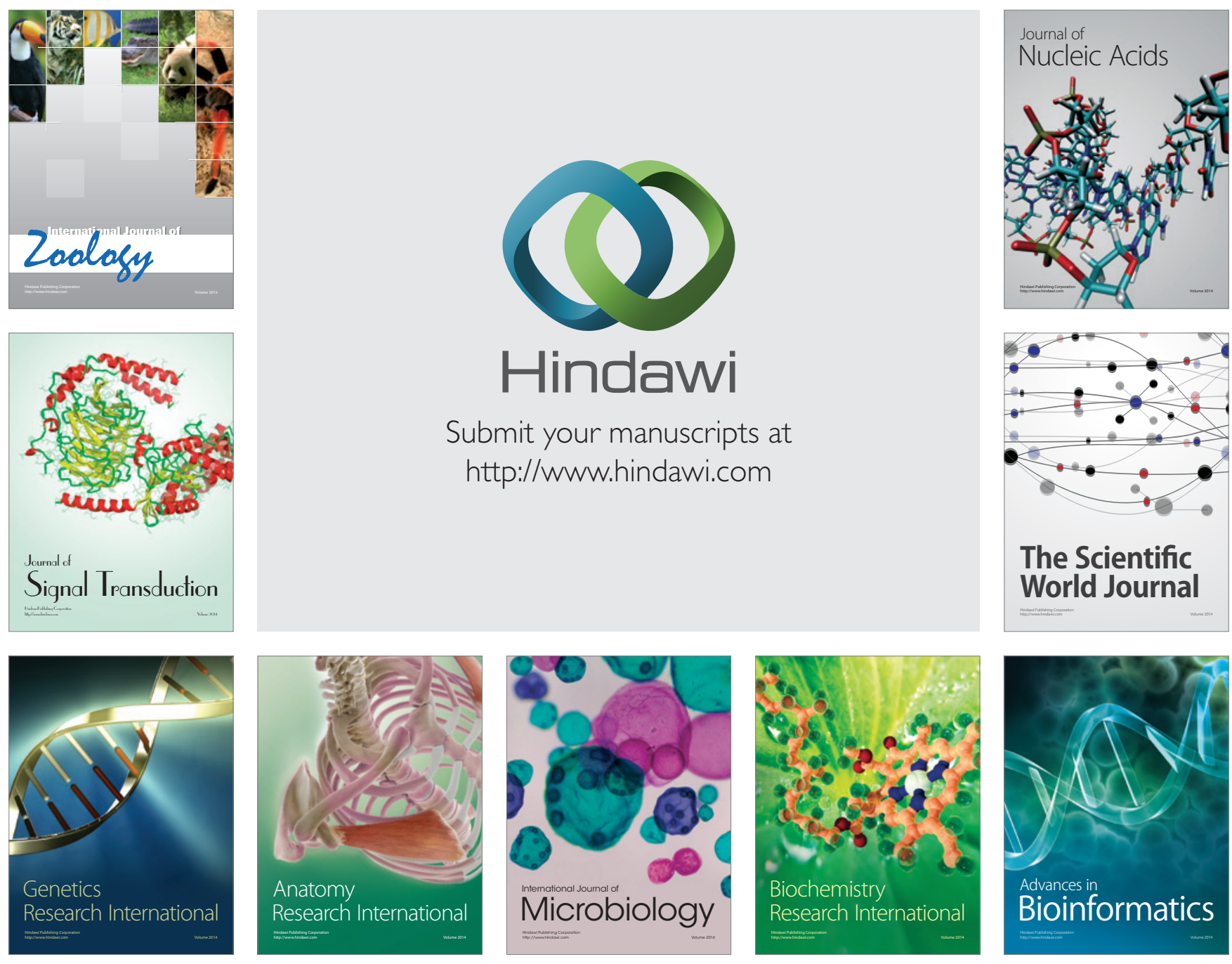

The Scientific World Journal
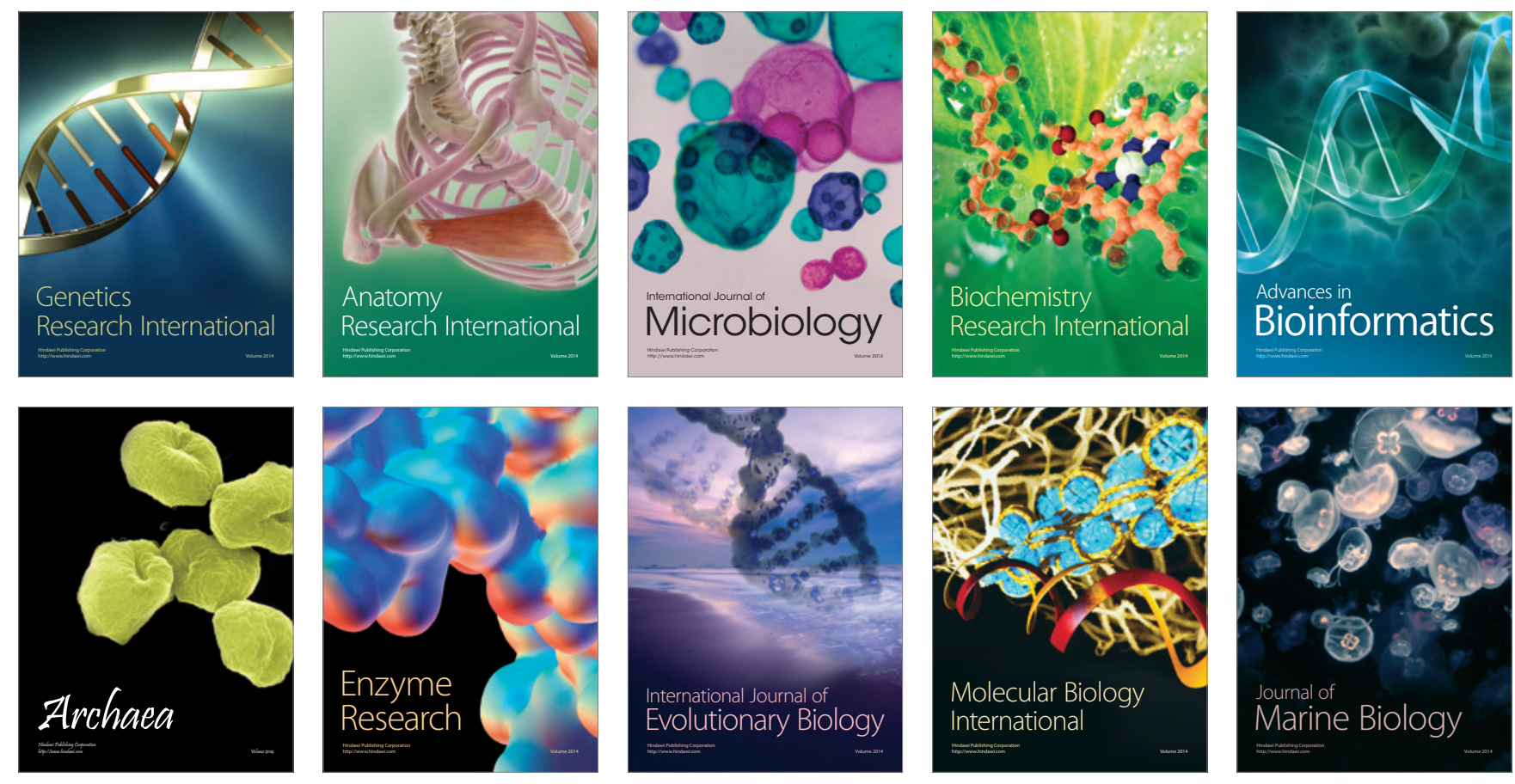